\title{
Group Judgments and Analytic Hierarchy Process
}

\author{
Tianjin University \\ Tianjin, China
}

\begin{abstract}
Human judgments are classified according to the objectives forthe judgment into three kinds, namely, scientific judgment which is a valid judgment with only purpose to reveal truth; objective judgment which is a judgment with an objective to make decision on affairs concerning the interests of individuals and/or individual groups within an organization which asks for a valid, credible and acceptable judgment; subjective judgment which is a judgment judged by one's own interest. The former two kinds of judgments should be made by a group of judges in order to reduce belief biases and biases due to lack of information. Decision makers who need good judgments about related affairs concerning their interests can trust a convener to organize and lead the group judgment. AHP which is an efficient tool to make the objective judgment should employ the group judgment. Some misuses of AHP neglecting the procedure of group judgment are illustrated and the right way in using AHP is re-emphasized.
\end{abstract}

\section{Human Judgment}

People are often making decisions during their daily lives based on their judgments. Computer can help people to judge complicated problems by indexing, processing, and analyzing information, but the important, principal and key parts of judgments come from human brains.

Human judgments are not only assessing probability or answering yes or no, good or bad, they also involve comparing, choosing, evaluating, forecasting and even decision making. Some of human judgments in turn involve several concerns which, for instance, are planning, generating a set of alternatives, setting priorities, choosing a best policy after finding a set of alternatives, allocating resources, determining requirements, insuring the stability of a system, optimizing, resolving conflict, etc.

The objects to be judged can be classified into following three kinds according to the time when the objects occur: past objects; present objects; future objects. 


\section{a. Judging past objects}

When people study the history of human society and/or the evolution of the nature, or explore the past secrets, they are judging the past objects. Those objects are all facts.

In making such kind of judgments, people have to collect, study and analyze related materials and information with help of various scientific methods including the chemical and physical examination and analysis of the collected materials, the textual criticism and research of the word materials, processing and filtering the gathered information. They then based on these studies put forward hypotheses and prove or test them, finally reach the conclusion of this study through inference. This kind of judgment may be called "scientific judgment". There is only one outcome of the scientific judgment which is valid because the object to be judged is the fact in the past. So, the scientific judgments is a valid judgment.

\section{b. Judging present objects}

When people study the unknown truth in scientific research, explore the secrets of the nature, make rating, evaluation, planning in social and economical affairs, and choose or decide something for their private business, they are judging the present objects.

The kind of judgment people employed in their research of seeking the unknown truth and the secrets of the nature is the same one as they used in judging the past facts--the scientific judgment. Although the investigated truth and the natural secrets have not yet been revealed, they are actually existed. Therefore, in studying such kind of objects, like truth and natural secrets, employing the scientific judgment is the only way to get final valid result.

When doing social judgment, such like rating, evaluation, planning, people should first identify the objectives of judgment, different objectives of the judgment lead to different outcomes of the judgment which in turn affect the interest of different people. Therefore the kind of judgment for social--economic affairs is not the absolute scientific judgment, but the "objective judgment". Here the author defines the objective judgment as a kind of judgment with objectives representing the interests of individual groups within an organization which asks for a valid, credible and acceptable judgment.

As the objective judgments are more popular and complicated, they will be explained further by following examples.

For raising the efficiency of the management of an organization which may be a government, an enterprise or an institution, it is often necessary to make evaluation on the effectiveness of administration. And the result of the evaluation will unavoidably affect the interests of individual persons and groups within the organization. In evaluating, the first task is to determine the system of indicators or criteria by which the attributes or complexes of attributes of the object to be judged can be judged. Here both the system of criteria and the value of each attribute should be judged by the judges according to their own utilities and interests. The judgment employed in this case is 


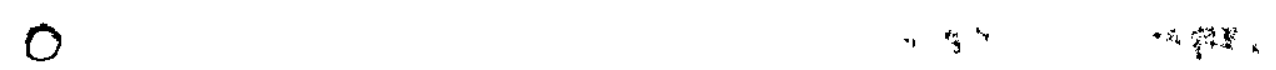

the objective judgment which is vaiid, credible and acceptable.

When promoting able staff members to more important positions in an organization in order to raise the administration ability, the organization managers should select from all qualified staff members the best ones to different important positions. This kind of judgment is also the objective judgment, because it is valid, credible and acceptable.

Another kind of judgment which concerns only private business may be called "subjective judgment", because people usually decide actions in their private lives by their own interests. only for crucial decision in private business which may lead to serious consequence, the judgment employed here belongs to objective judgment.

\section{c. Judging future objects}

Judgments about future objects (events, phenomena, or conditions) include forecasting, planning and decision making. The characteristics of this kind of judgment is uncertainty, because the objects to be judged have not yet occurred.

Forecasting is a statement about the future events. According to the objects to be predicted, forecasting may also be classified into several kinds.

When forecasting the natural phenomena, like natural disasters, earthquakes, typhoon, or weather forecast, the occurrence and variation of which is audience-independent, people can judge the probability of this occurrence, including time, place and strength. This also belongs to the scientific judgment.

When forecasting the social-economic affairs which can be influenced by human activities, the objective of forecasting is to make decision in order that the bad (or the good) influence due to the future changes of affairs can be reduced (or increased). Sometimes people forecast the future social-economic affairs with a goal to create a better life in the future for themselves, they try to find out in which way they can achieve their objectives through forecasting. This kind of judgment employed in forecasting, planning and decision making belongs to objective judgment also.

In summary, human judgments can be classified into the following three kinds:

Scientific judgment---- a valid judgment with only objective to reveal truth;

Subjective judgment----- a judgment judged by one's interest;

objective judgment----- a judgment with objectives

representing the interests of

individuals and/or individual groups within an organization which asks for a valid, credible and acceptable judgment.

Table 1 explains the different kinds of human judgments.

How can people judge?

People who want to employ the scientific judgment must have experience and knowledge about the objects to be judged and also be able to do logical inference and analysis. He who wishes to use objective judgment' as a tool to make decisions, planning or 
evaluation for some business must have practical experience on economic, managerial and personal affairs in that business, and must be able to find out various interrelationships in that business. When making subjective judgment, one should know clearly what he or she wants and likes.

Table 1

\begin{tabular}{|c|c|c|c|}
\hline & scientific & objective & subjective \\
\hline Judging past & Past facts & & \\
\hline $\begin{array}{l}\text { Judging } \\
\text { present }\end{array}$ & $\begin{array}{l}\text { seek unknown } \\
\text { truth }\end{array}$ & $\begin{array}{l}\text { Judge social- } \\
\text { economic } \\
\text { affairs } \\
\text { evaluate } \\
\text { effectiveness } \\
\text { of an } \\
\text { organization } \\
\text { choose some } \\
\text { things private } \\
\text { business with } \\
\text { serious } \\
\text { consequences }\end{array}$ & $\begin{array}{l}\text { Private } \\
\text { business }\end{array}$ \\
\hline judging future & $\begin{array}{l}\text { Forecast } \\
\text { audience } \\
\text { independent } \\
\text { events and } \\
\text { phenomena }\end{array}$ & $\begin{array}{l}\text { Forecast } \\
\text { future } \\
\text { audience- } \\
\text { dependent } \\
\text { events and } \\
\text { phenomena }\end{array}$ & \\
\hline $\begin{array}{l}\text { Correct } \\
\text { judgment }\end{array}$ & $\begin{array}{l}\text { one one } \\
\text { and with } \\
\text { only proba- } \\
\text { one bility }\end{array}$ & More than one & More than one \\
\hline
\end{tabular}

In order to make good and satisfactory judgment, one should be able to make freely his judgments through deliberation, to have time to think independently and also to have chance to discuss with others and to get feedback information from previous group judgment.

There are inherent biases in individual judgments, the experts who are mastering their domain expertise often make judgments with too strong-self-belief which will inevitably cause a kind of bias. Belief bias refers to a tendency for people to generate conclusions to their prior beliefs and to be more critical in their evaluation of conclusions which conflict with their beliefs. [2] 


\section{Group Juagments [3]}

For the three kinds of human judgments mentioned above, good conclusions of scientific and objective judgments can only be drawn by help of group judgment. Reasons for using group judgment may be explained as follows.

\section{a. Scientific judgments}

Reasons for using group judgments in judgments are: (1) The objects judged by scientific judgment are all facts and/or truth which involve many different domains of science. In order to make good and satisfactory judgment it is necessary to select a group of experts from different domains of science to provide reliable information required for making scientific judgment. It is a necessary condition in selecting experts for group judgment that the number of domain experts should be large enough so that their grouped domains cover the whole domains needed to judge the objects. This is called the domain coverage requirement. [4]

(2) The inherent bias of individual judgment may be reduced by group judgment.

\section{b. objective judgments}

(1) The objects judged by objective judgment are socialeconomic affairs where judgment is closely related to decision making, the result of which will affect directly or indirectly people joining the judgment. In order to make appropriate and" acceptable judgment, people representing different interests in the objects judged should be invited to make group judgment. This is also the domain coverage requirement.

(2) The inherent bias of individual judgment may be reduced by group judgment.

For correct generation of group judgment, the following three things are important: 1) choosing suitable participants in group judgment; 2) organizing the group and leading the judging process; and 3) making interaction between decision makers and judges. There are three kinds of people in organizing a group judgment: decision makers, conveners and experts.

The decision maker who is responsible to the object (socialeconomic affair) needs a valid, credible and acceptable judgment about the object judged to make correct decision or management. He may organize and lead the group to generate the judgment by

himself or trust a convener. The convener, or the organizer (sometimes may be the decision maker himself), as an agent for the decision maker, organizes the judgment group by selecting a number of appropriate experts or other interested people and carries out group judgment. The convener should understand the process of group judgment and is self-confident enough to lead the group through the process. The result of judgment should be accepted by the decision maker. If he feels some parts in the judgment unacceptable, the judgment will be rejudged.

There are several important steps in the process of group judgment: 1) identifying the objectives and requirements of the judgment; 2) listing the specialty domains and fields of experience concerning the object to be judged so that necessary experts can be 
selected to form a judgment group with whole coverage; 3) choosing the right experts; 4) leading the group through the process of judgment so that all participants can make their judgments independently and can revise their previous judgment through debate, idea exchange and feedback of information from the result of previous group judgment; 5) sending the result of group judgment to the decision maker. If the decision maker finds something improper in the judgment, he may interact with the group and ask them to rejudge it.

\section{Group Judgment and AHP}

The main aspects of the contribution provided by the Analytic Hierarchy Process (AHP) are: the difficulty in measuring the quality of the attributes of some social events can be handled by pairwise comparison; the logical inconsistency arising from studying complicated events can be checked by consistency indexing AHP; the complexity in judging an event can be reduced by decomposing it into simple hierarchy structure. For these reasons, the AHP has been widely used by leaders of many organizations to help them make decisions.

As the objects judged by use of AHP are mostly audience-dependent affairs, the judgments made with AHP are mostiy the objective judgments where the group judgments are used. Therefore the AHP should be carried out along the procedure for group judgment mentioned in section 2 .

However, some people often misuse AHP, at least in china, in group judgment. The following three cases can illustrate the misuse of AHP.

(1) The convener distributes the AHP forms designed by himself to the participants in the group and asks them to fill in the forms with their judgments from pairwisely comparing the entries listed in the forms and to make individual judgment matrix which will be collected by the convener. The convener then takes the average value of each corresponding entry in all individual judgment matrixes to form an aggregated judgment matrix. It is the misuse of AHP if this aggregated judgment matrix is used as the basis to rank the related priority of alternatives.

(2) The convener distributes the AHP forms designed by himself to the participants in the group and asks them to do pairwise comparison and find out the priority order of related elements based on the individual judgment matrix. The convener then takes the average value of each weight denoting the priority order of the related element given by each participant. It is also a misuse of AHP if the convener regards these average values as the numbers representing the priority order.

(3) The convener distributes whole set of the AHP forms, including forms of matrixes on all levels in the hierarchy structure for the problem, designed by himself, to the participants of the group and asks them to do all the pairwise comparison and rank all the priorities for the problem. The final priority of related alternatives obtained by each participant with AHP is collected by the convener, the latter then makes the aggregated order of priority of related alternatives by averaging. It is a 
misuse of AHP if this order of priority is used as an AHP priority. In all these cases, the participants are chosen by the convener more or less at will and they have not been asked to join the discussion with others on the structure of the hierarchy and the system of criteria for pairwise comparison. How can the participant make good judgment when he disagrees with the hierarchy structure and/or the system of criteria, and/or when he feels that the important items have not been included in the systems of criteria while those included are not important? Under back to back condition, the results of pairwise comparisons by two participants with different interests and/or experiences are quite different. Taking the average value of their individual

comparisons as the aggregated result is entirely nonsense. Apparently, when one says yes about certain things and the other says no, how can we say that the "average" opinion of them is "not yes nor no" or "either yes or no"? Likewise, when using numbers 1 to 9 representing the result of comparison of the strength of two elements $A$ and $B$ in AHP, when one takes $1 / 9$ representing his comparison of $A$ to $B$, $i . e .$, in his opinion $A$ is absolutely more unimportant than $B$, and the other takes 9 as his comparison of $A$ to $B$, i.e., in his opinion $A$ is absolutely more important than $B$. Surely we cannot say their common opinion is the numerical value 1 which means $A$ is as important as $B$. This average means nothing.

In objective judgment the individual judgments of each. participant are usually different. They cannot get a commonly agreeable result unless through debate, compromise and bargaining [1].

The correct way in using AHP for judgment which will be emphasized again is listed as follows.

(1) The convener should select a group of participants with whole coverage of both specialty domains and experience, invite them to attend a series of meetings to identifying the objectives for judgment, break down the problem to be judged into -its elementary components and structure the hierarchy, define the variables and the system of criteria.

(2) The convener then leads the process of pairwise comparison. The participants may compare the elements in the judgment matrixes indenpently, but the final comparison matrixes as well as the final pairwise comparisons of elements should be obtained through debate or compromise. The final result of judgment--the ordering priority of the related alternatives--can then be derived from the final comparison matrixes and it is accepted by all the participants in the group.

(3) The final order of the priority thus obtained should be examined by the decision maker. The judgment process is completed if the decision maker accepts the result, otherwise the result should be rejudged again by repeating steps (1), (2).

When AHP is used in scientific judgment, the results of individual comparisons are usually the same. The differences due to biases in individual comparisons are small and can be reduced by various means of aggregating such as arithematic mean, geometric mean, minimization of square sum errors and others [5]. 
1. Thomas L. Saaty, "The Analytic Hierarchy Process," McGraw Hill, New York, 1980.

2. Jonathan St. B. T. Evans, "Beliefs and Expectation as Causes of Judgmental Bias", in G. Wright and A. Ayton, edt., Judgmental Forecasting, John Wiley Sons Ltd., New York, 1987.

3. Andy Lock, "Integrating Group Judgments in subjective Forecasts", in G. Wright and A. Ayton edt., Judgmental Forecasting, John Wiley Sons Ltd., New York, 1987.

4. Tadeusz Galanc and Jan Mikus, "The Choice of an Optimum Group of Experts", Technology Forecasting and Social Change 30, 1986.

5. Wang Ruhua, Li Guangquan and $\mathrm{Xu}$ Shubo, "An Approach to Synthesising Judgment", Preprints of ISAHP, Tianjin, 1988 . 